American Journal of Applied Sciences 6 (6): 1175-1179, 2009

ISSN 1546-9239

(C) 2009 Science Publications

\title{
Development of Nanostructured Stress Free Pt-Rich FePt Films for Micro Electro Mechanical System Applications
}

\author{
${ }^{1}$ T.M. Selvakumari, ${ }^{2}$ R.N. Emerson and ${ }^{3}$ S. Ganesan \\ ${ }^{1}$ Department of Physics, Angel College of Engineering and Technology, \\ Tirupur-641665, Tamilnadu, India \\ ${ }^{2}$ Department of Physics, Karunya University, Coimbatore-641114, Tamilnadu, India \\ ${ }^{3}$ Department of Physics, Government College of Technology, Coimbatore-641001, Tamilnadu, India
}

\begin{abstract}
Problem statement: The electroplating technique is especially interesting due to its low cost, high throughput and high quality of deposit. Magnetic thin films are extensively used in various electronic devices including high density recording media and Micro Electro Mechanical (MEMS) devices. So we examined FePt films and give good magnetic properties. Approach: The Pt-rich FePt alloys were electrodeposited galvanostatically by various temperature baths. Results: The elemental percentage of Pt in the film was very high determined by X-ray spectroscopy. Surface characterization was carried out by using X-Ray Diffractometer (XRD) and Scanning Electron Microscope (SEM).The magnetic properties determined by Vibrating sample magnetometer. Hardness and adhesion of the films were also discussed. Conclusion/Recommendation: The films were soft magnetic character of lower temperature bath and become a hard magnetic character of higher temperature bath. Therefore this magnetic films could be an important material for incorporate in Micro electro mechanical devices.
\end{abstract}

Key words: FePt, electrodeposition, magnetic film, magnetic properties

\section{INTRODUCTION}

With the progress in the field of Micro Electro Mechanical System (MEMS) technologies ${ }^{[1-5]}$ there has been growing interest in developing electroplated, nanostructured soft and hard magnetic materials ${ }^{[6,7]}$ for microactuators, micromotors and microswiches. The possibilities of these electroplated materials, retaining hard and soft magnetic properties up to several microns thickness, gives researches opportunity to explore them for micro fabrication of MEMS devices. Recently, much effort is being made to electrodeposits also materials of the group of L10 ordered alloys, like $\mathrm{FePt}^{[8,9]}$ and $\mathrm{CoPt}^{[10,11]}$, because they exhibit a significantly higher uniaxial magneto crystalline anisotropy. As the formation of the L10 phase is kinetically hindered at room temperature, post annealing of the films is necessary. Electrodeposited and post annealed $\mathrm{FePt}$ and $\mathrm{CoPt}$ films can reach coercivities exceeding $1 \mathrm{~T}^{[11]}$.

In the present study we investigated in detailed the effects of bath temperature on electrodeposited Pt rich magnetic FePt films of various deposited time and current density. Also we discussed their structural and magnetic characterization.

\section{MATERIALS AND METHODS}

A copper substrate of size $1.5 \times 5.0 \mathrm{~cm}$ as cathode and pure steel of same size as anode were used for galvanostatic electrodeposition experiments. Current for electrodeposition was passed from a regulated directed current unit. Analytical reagent grade chemicals were used to prepare baths. An adhesive tape was used to mask off all the substrate except the area on which deposition of film was desired. Each substrate was buffed for removing scratches in a mechanical polishing wheel using a buffing cloth coated with aluminum oxide abrasive. Buffed substrates were decreased using acetone. Before electrodeposition these substrates were electrocleaned in an alkaline electrocleaning bath. The bath contained sodium hydroxide: $7.0 \mathrm{~g} \mathrm{~L}^{-1}$; sodium carbonate: $20.0 \mathrm{~g} \mathrm{~L}^{-1}$; trisodium phosphate: $9.0 \mathrm{~g} \mathrm{~L}^{-1}$ and sodium metasilicate: $24.0 \mathrm{~g} \mathrm{~L}^{-1}$. The bath was operated at $3.0 \mathrm{~A} \mathrm{dm}^{-2}$. After electrocleaning the substrates were rinsed in distilled water. FePt films wee electrodeposited on polycrystalline $\mathrm{Cu}$ substrate from a single bath containing $1 \mathrm{~m} \mathrm{H} 2 \mathrm{PtCl} 6,0.1$ (NH4)2SO4 and $0.1 \mathrm{~mol} \mathrm{~L}^{-1}$ FeSO4. The solution $\mathrm{pH}$ was adjusted to 3 by adding a small amount of either sulfuric acid or hydrochloric acid. For depositing films using dc plating at current

Corresponding Author: R.N. Emerson, Department of Physics, Karunya University, Coimbatore-641114, Tamilnadu, India 
densities varying from $1-3 \mathrm{~mA} \mathrm{~cm} \mathrm{~cm}^{-2}$ at various temperature $30,50,70^{\circ} \mathrm{C}$ with various time of deposition.

The thickness of the deposits was tested using digital micrometer (Mitutoyo, Japan). Magnetic properties of deposited films were studied using vibrating sample magnetometry. In this technique the material under study was contained in a sample holder, which was centered in the region between the pole pieces of a laboratory magnet. A slender vertical sample rod connects the sample holder with a transducer assembly. The transducer converts a sinusoidal alternating current drive signal into a sinusoidal vertical vibration of the sample rod. Coils mounted on the pole pieces of the magnet pick up the signal resulting from the sample motion. X-Ray Diffractometry (XRD) and Scanning Electron Microscopy (SEM) were used to study the structure and morphology of these magnetic films respectively. From XRD data crystallite size of the deposited CoNiP and film stress were calculated. Percentage of elements such as cobalt, nickel and phosphorous present in the deposits were obtained as follows. For elemental analysis CoNiP film was electrodeposited on stainless steel substrate to ensure easier peeling-off of the film. After deposition the film was peeled off from the substrate. It was dissolved in $3: 1 \mathrm{v} / \mathrm{v}$ of $\mathrm{H}_{2} \mathrm{SO}_{4}$ and $\mathrm{HNO}_{3}$ and the percentage composition was obtained using energy dispersive X-Ray Spectroscopy (EDS). Hardness of the deposit was obtained using Vicker's hardness tester using diamond intender method. Adhesion of the film was tested by bend and by scratch or chisel test. These tests are widely used in the field of electroplating ${ }^{[12]}$.

\section{RESULTS}

Surface characterization: X-ray diffraction patterns of various $\mathrm{FePt}$ electrodeposits produced from various temperature bath like 30,50 and $70^{\circ} \mathrm{C}$ for $1.0 \mathrm{~mA} \mathrm{~cm}{ }^{-2}$ and $30 \mathrm{~min}$ were fixed current density and time of deposition respectively for electrodeposition (Fig. 1). The data obtained from the XRD pattern compared with standard data and were found to have face centered tetragonal structure and exhibited (221) plane predominantly. From the XRD pattern peak, stressed in the film was calculated using the formula: Youngs modulus $=$ stress $/$ strain. The results shown in Table 1.

Crystalline size of the deposits were calculated from the XRD pattern using the formula:

Crystalline size $=0.9 \lambda / \mathrm{B} \cos \theta$. These values clearly show that the crystallite size of the FePt deposit obtained by electrodeposition process are in the nano scale. The crystallite size of deposits are shown in Table 1.

Table 1: Effect of bath temperature on the structural and mechanical properties of FePt film electrodeposited at $1 \mathrm{~mA} \mathrm{~cm}^{-2}$ for

\begin{tabular}{lllllr}
\hline $\begin{array}{l}\text { Bath } \\
\text { temperature } \\
\left({ }^{\circ} \mathrm{C}\right)\end{array}$ & $\begin{array}{l}\text { Crystalline } \\
\text { size }(\mathrm{nm})\end{array}$ & $\begin{array}{l}\text { Vickers } \\
\text { hardness } \\
(\mathrm{VHN})\end{array}$ & $\begin{array}{l}\text { Internal } \\
\text { stress } \\
(\mathrm{MPa})\end{array}$ & $\begin{array}{l}\text { Film composition } \\
(\text { at } \%)\end{array}$ & \\
\hline 30 & 76 & 268 & 163 & 5.0 & 95.0 \\
50 & 22 & 275 & 152 & 3.6 & 96.4 \\
70 & 18 & 317 & 140 & 2.1 & 97.9 \\
\hline
\end{tabular}

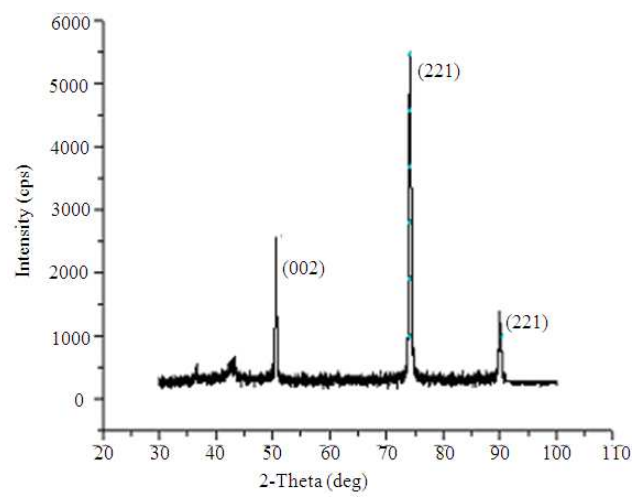

(a)

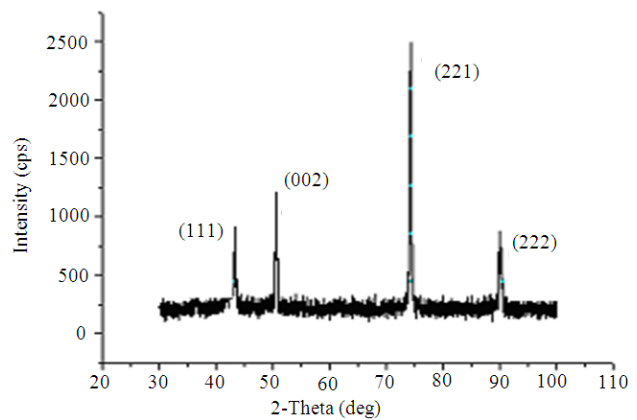

(b)

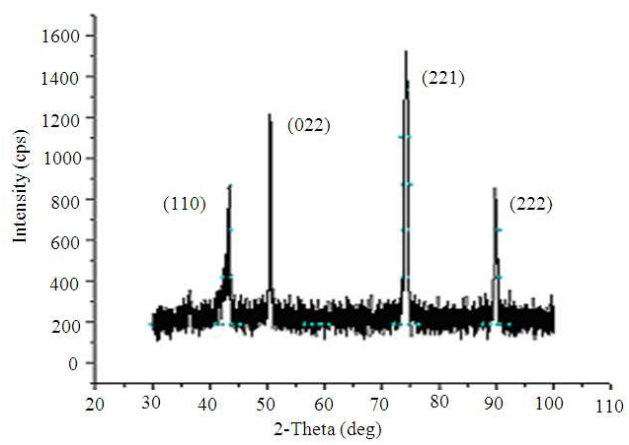

(c)

Fig.1: XRD patterns for electrodeposited FePt film at current density: $1 \mathrm{~mA} \mathrm{~cm} \mathrm{~cm}^{-2}$, deposition time $30 \mathrm{~min}$ and various temperatures bath $(\mathrm{a}): 30^{\circ} \mathrm{C}$, (b): $50^{\circ} \mathrm{C},(\mathrm{c}): 70^{\circ} \mathrm{C}$ 
Am. J. Applied Sci., 6 (6): 1175-1179, 2009

Table 2: Effect of bath temperature at $30^{\circ} \mathrm{C}$, time of deposition and Current density on the thickness and magnetic properties of electrodeposited FePt film

\begin{tabular}{|c|c|c|c|c|c|c|}
\hline $\begin{array}{l}\text { Current density } \\
\left(\mathrm{mA} \mathrm{cm}^{-2}\right)\end{array}$ & $\begin{array}{l}\text { Time of } \\
\text { deposition (min) }\end{array}$ & $\begin{array}{l}\text { Thickness of } \\
\text { deposit (um) }\end{array}$ & $\begin{array}{l}\text { Magnetic } \\
\text { saturation (emu) }\end{array}$ & Remanent $(\mathrm{emu})$ & Coercivity (Oe) & Squareness \\
\hline \multirow[t]{3}{*}{1} & 15 & 3.0 & 0.733 & 0.013 & 500 & 0.017 \\
\hline & 30 & 3.2 & 0.718 & 0.019 & 600 & 0.026 \\
\hline & 60 & 3.5 & 0.715 & 0.024 & 700 & 0.033 \\
\hline \multirow[t]{3}{*}{2} & 15 & 3.5 & 0.720 & 0.034 & 600 & 0.047 \\
\hline & 30 & 4.0 & 0.700 & 0.037 & 700 & 0.052 \\
\hline & 60 & 4.2 & 0.680 & 0.039 & 800 & 0.057 \\
\hline \multirow[t]{3}{*}{3} & 15 & 5.0 & 0.650 & 0.045 & 700 & 0.069 \\
\hline & 30 & 5.3 & 0.620 & 0.050 & 800 & 0.080 \\
\hline & 60 & 5.6 & 0.600 & 0.052 & 900 & 0.086 \\
\hline
\end{tabular}

Table 3: Effect of bath temperature at $50^{\circ} \mathrm{C}$, time of deposition and current density on the thickness and magnetic properties of electrodeposited FePt film

\begin{tabular}{lllllcc}
\hline $\begin{array}{l}\text { Current density } \\
\left(\mathrm{mA} \mathrm{cm}^{-2}\right)\end{array}$ & $\begin{array}{l}\text { Time of } \\
\text { deposition }(\mathrm{min})\end{array}$ & $\begin{array}{l}\text { Thickness of } \\
\text { deposit }(\mathrm{um})\end{array}$ & $\begin{array}{l}\text { Magnetic } \\
\text { saturation }(\mathrm{emu})\end{array}$ & Remanent $(\mathrm{emu})$ & Coercivity (Oe) & Squareness \\
\hline 1 & 15 & 3.0 & 0.427 & 0.024 & 700 & 0.056 \\
& 30 & 3.2 & 0.418 & 0.025 & 800 & 0.059 \\
& 60 & 3.5 & 0.400 & 0.028 & 900 & 0.070 \\
& 15 & 3.5 & 0.420 & 0.030 & 700 & 0.070 \\
& 30 & 4.0 & 0.400 & 0.033 & 800 & 0.080 \\
& 60 & 4.2 & 0.380 & 0.037 & 900 & 0.097 \\
& 15 & 5.0 & 0.350 & 0.042 & 1000 & 0.114 \\
& 30 & 5.3 & 0.320 & 0.043 & 1100 & 0.134 \\
& 60 & 5.6 & 0.300 & & & 0.140 \\
\hline
\end{tabular}

Table 4: Effect of bath temperature at $70^{\circ} \mathrm{C}$, time of deposition and Current density on the thickness and magnetic properties of electrodeposited FePt film

\begin{tabular}{|c|c|c|c|c|c|c|}
\hline $\begin{array}{l}\text { Current density } \\
\left(\mathrm{mA} \mathrm{cm}^{-2}\right)\end{array}$ & $\begin{array}{l}\text { Time of } \\
\text { deposition ( } \mathrm{min})\end{array}$ & $\begin{array}{l}\text { Thickness of } \\
\text { deposit (um) }\end{array}$ & $\begin{array}{l}\text { Magnetic } \\
\text { saturation (emu) }\end{array}$ & Remanent (emu) & Coercivity (Oe) & Squareness \\
\hline \multirow[t]{3}{*}{1} & 15 & 3.0 & 0.233 & 0.045 & 1000 & 0.193 \\
\hline & 30 & 3.2 & 0.218 & 0.048 & 1100 & 0.220 \\
\hline & 60 & 3.5 & 0.215 & 0.050 & 1200 & 0.232 \\
\hline \multirow[t]{3}{*}{2} & 15 & 3.5 & 0.214 & 0.054 & 1200 & 0.252 \\
\hline & 30 & 4.0 & 0.212 & 0.057 & 1300 & 0.268 \\
\hline & 60 & 4.2 & 0.200 & 0.059 & 1400 & 0.295 \\
\hline \multirow[t]{3}{*}{3} & 15 & 5.0 & 0.150 & 0.065 & 1500 & 0.433 \\
\hline & 30 & 5.3 & 0.120 & 0.067 & 1600 & 0.558 \\
\hline & 60 & 5.6 & 0.100 & 0.069 & 1700 & 0.690 \\
\hline
\end{tabular}

Electrodeposited FePt films from all three temperature bath as mentioned in XRD studies were subjected to SEM studies. The micrographs are shows in Fig. 2. In general, microstructure of the FePt film is greatly influenced by the temperature of bath. Elements present in the film were analyzed by Energy dispersive $\mathrm{X}$-ray spectroscopy and the results are shows in Table 1.

Mechanical properties: Adhesion of the film with the substrate is tested by bend test and scratch test. It showed that the film is having good adhesion with the substrate. Hardness of the film increases when the film deposited from bath temperature increases. This may also be due to the lower stress associated with FePt film. The results are reported in Table 1.

Magnetic properties: Electrodeposition studies were carried out using different bath temperature. Table 2 shows the results of electrodeposition of FePt and their magnetic properties. The temperature of the bath varies at $50^{\circ} \mathrm{C}$ and electrodeposition studies were carried out. The thickness of the film for various current densities and time of deposition as shown in Table 3.

Table 4 shows the effect of deposited film by higher bath temperature $70^{\circ} \mathrm{C}$. The thickness of deposit increases with increase in current density. The change in magnetic properties was because of the higher percentage of $\mathrm{Pt}$ in the films make low stress present in the film.

\section{DISCUSSION}

From XRD data the crystalline structure found in FePt film is fct produced from a bath at low temperature has high stress and this is due to random crystal orientation during electrodeposition. But on the 


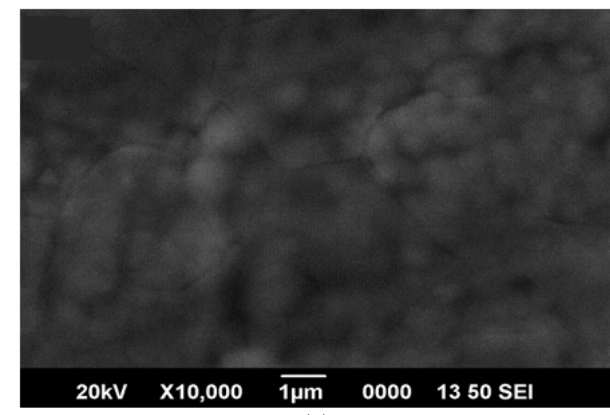

(a)

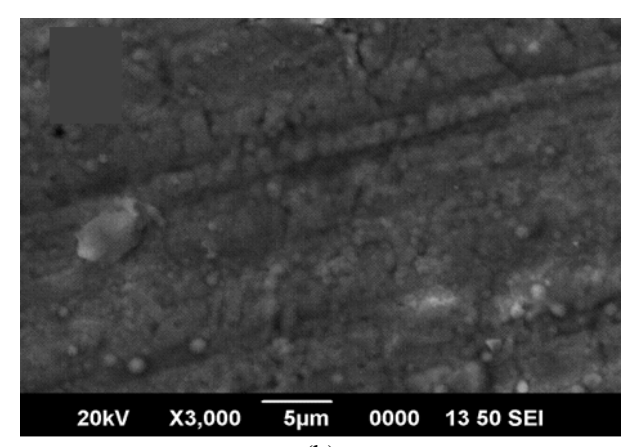

(b)

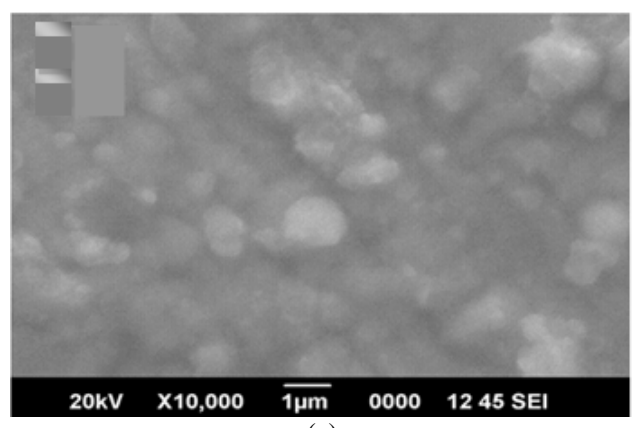

(c)

Fig. 2: SEM images of FePt films electrodeposited for 30min, Current density: $1 \mathrm{~mA} \mathrm{~cm}{ }^{-2}$ at temperature (a): $30^{\circ} \mathrm{C},(b): 50^{\circ} \mathrm{C},(\mathrm{c}): 70^{\circ} \mathrm{C}$

film from higher temperature bath has low stress. This is due to uniform crystal orientation during electrodeposition. This analysis reveals the effect of film from higher temperature bath on the crystallite size of the deposit. The morphology of the film deposited at low temperature bath appeared crevice pattern with crack, grains are formed in random order and it also appears less bright. In the film deposited at high temperature, the grain sizes are visible and granular form .They are in more order with fct structure.

All deposits, which were subjected to analysis, EDS have grater than $95 \%$ Pt content. The films obtained from various temperatures and current densities are $\mathrm{Pt}$ rich films having high magnetic properties. The films are high hardness and good adhesion.

When the low temperature bath $\left(30^{\circ} \mathrm{C}\right)$ used for deposition, the thickness of the deposit increases with increase in current density and time of deposition. Films are dull in appearance and having pits. Films are having very low coercive and remanent values. In the electrodeposition studies films produced $\left(50^{\circ} \mathrm{C}\right)$ were uniform and bright. This because the orientation of crystallization uniformly during electrodeposition by adsorbing itself on the initially deposited crystals. The magnetic properties of the high temperature bath $\left(70^{\circ} \mathrm{C}\right)$ films revealed that these films are having a high coercive and low remanent value when compared to the deposit obtained from films deposited from low temperature bath.

As the average crystallite size of the films are in nanoscale, considerable change in magnetic behavior can occur. When the crystalline size approaches high nanolevel, the domain wall thickness is comparable to the crystalline size the coercivity found to increase. Analysis of crystallite size, microstructure and magnetic properties confirm that the origin of magnetic properties is because of the strongly interacting array of single domain crystals. This is mainly due to the films from high temperature bath.

\section{CONCLUSION}

A FePt film having good hard magnetic properties can be electrodeposited from the high temperature bath containing percentage of $\mathrm{Pt}$ is rich. In the low temperature bath the film character is change it showed soft magnetic character. It also increases the film stress, which is a cause for cracked film. The high temperature bath films are lower stress which are used in MEMS devices. Hardness of the film also increase in higher temperature bath films which are having high coercivity value and low remanent values. Also these films have good adhesion with the substrate and their crystalline sizes are nano scale.

\section{REFERENCES}

1. Cugat, O. et al., 2003. Magnetic micro-actuators and systems. IEEE. Trans. Magnet., 39: 3607. DOI: 10.1109/TMAG.2003.816763

2. Roy, S. et al., 2005. Pulse reverse plating for integrated magnetic on Si. J. Magnetism Magnet. Mater., 1524: 290-29. DOI: 10.1016/j.jmmm.2004.11.566

3. Rhen, F.M. et al., 2005.Thick film permanent magnets by membrane electrodeposition. J. Applied Phys., 97: 113908-113908-4. DOI: 10.1063/1.1923587 
4. Lee, K.H. et al., 2002. Magnetic properties of selfordered ferromagnetic nano wires by ac electroforming. J. Applied Phys., 91: 8513. http://link.aip.org/link/JAPIAU/91/8513/1

5. Emerson, R.N. et al., 2007. Effect of organic additives on the magnetic properties of electrodeposited Conip hard magnetic films. Thin Solid Films, 515: 3391-3396. DOI: 10.1016/j.tsf.2006.09.034.

6. Pattnaik, G. et al., 2006. Electrodeposition of hard magnetic films and microstructures. J. Elect. Acta, 852: 2755-2764. 10.1016/j.electacta.2006.07.062

7. Park, H.D. et al., 2006. Microstructure and magnetic properties of electrodeposited CoPtP alloys. J. Applied Phys., 99: 08N305-08N305-3. DOI: $10.1063 / 1.2173229$
8. Leistener, K. et al., 2004. Phase formation, microstructure and hard magnetic properties of electrodeposited FePt films. J. Applied Phys., 95: 7267-7269. DOI: 10.1063/1.1667438

9. Moffat, T.P. et al., 2008. Oxygen Reduction Kinetics on Electrodeposited $\mathrm{Pt}, \mathrm{Pt}_{100-\mathrm{x}} \mathrm{Ni}_{\mathrm{x}}$ and $\mathrm{Pt}_{100-\mathrm{x}} \mathrm{Co}_{\mathrm{x}}$. Electrochem. Solid State Lett., 156: B238-B251. http://dx.doi.org/10.1149/1.3033515

10. Eagleton, T.S. et al., 2005. Electrodeposition of CoxPt1-x thin films. J. Electrochem. Soc., 152: C27-C31. DOI: 10.1088/0022-3727/38/6/020

11. Leistener, K. et al., 2003. Highly coercive electrodeposited FePt films by postanealing in hydrogen. Appl. phys. Lett., 85: 3498-3500. http://link.aip.org/link/?APPLAB/85/3498/1 